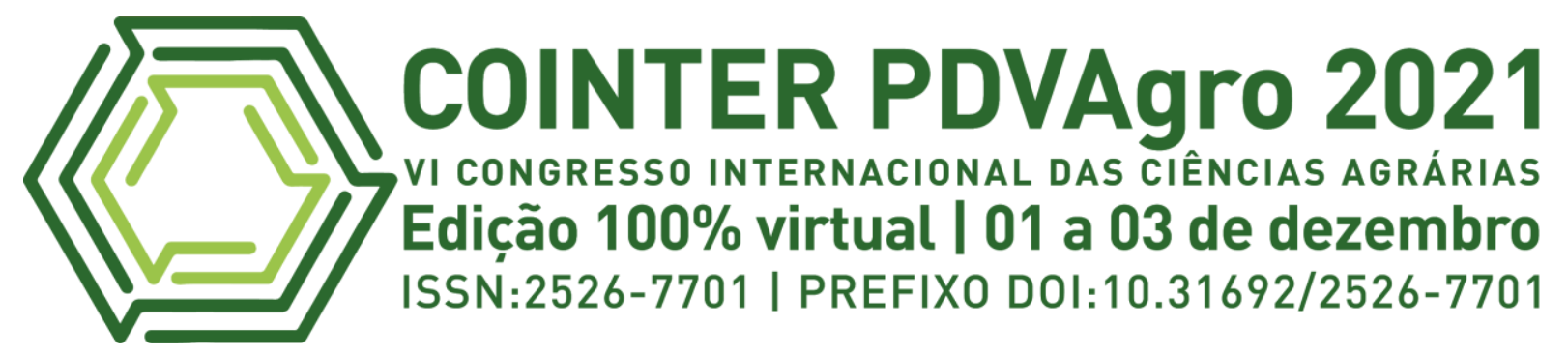

\title{
UTILIZAÇÃO DE SEMENTES PARA BIOJÓIAS POR ARTESÕES EM FEIRAS DE ARTESANATOS EM BELÉM - PA.
}

\author{
USO DE SEMILLAS PARA BIOJEWELAS POR ARTESANÍA EN FERIAS DE \\ ARTESANÍA EN BELÉM - PA.
}

\section{USE OF SEEDS FOR BIOJEWELS BY HANDICRAFTS AT HANDICRAFT FAIRS IN BELÉM - PA.}

\author{
Apresentação: Comunicação Oral
}

\begin{abstract}
João Lucas Sauma Alvares'; Thamires Kensiane Dias Alburg²; Giovana Samara Da Silva Seabra ${ }^{3}$; Michele Taiana Lobato De Oliveira ${ }^{4}$; Danilo Mercês Freitas ${ }^{5}$
\end{abstract}

DOI: https://doi.org/10.31692/2526-7701.VICOINTERPDVAgro.0044

\begin{abstract}
RESUMO
Em decorrência da grande biodiversidade a qual a Amazônia possui as práticas a qual fomentam e aproveitam essa biodiversidade devem ser valorizadas como intuito de demostrar o verdadeiro potencial do uso das florestas em pé, com isso, destacar-se a fabricação das biojóias, que embora possuam grande importância ambiental o seu destaque ainda é pequeno quando relacionado aos outros produtos de manejos florestais não madeireiros, como o extrativismo de frutos e óleos. Deste modo, as biojóias assim como os outros produtos advindos das atividades não madeireiras possuem um grande valor de sustentabilidade, atendendo as exigências atuais do mercado mundial, porém, a fabricação das biojóias ainda agrega o estético e o cultural e dessa forma as biojóias seriam denominadas como adornos produzidos artesanalmente com a utilização de recursos naturais que valorizam e difundem a cultura nacional e a biodiversidade existente no país e que garantem a sustentabilidade e a renda de famílias, assim atendendo os quesitos sustentáveis, ecológico e social. Assim o objetivo dessa pesquisa foi identificar as sementes utilizadas no artesanato nas principais feiras e praças de Belém e região metropolitana, além de verificar os principais produtos confeccionados com sementes e os valores pelos quais esses produtos são comercializados, para isso foi planejado e aplicado questionários aos artesoes produtores de biojóias localizados em três feiras no município de Belém - PA. Nesse sentido, a maior porcentagem dos produtores de biojóias em Belém são mulheres que possuem a faixa etária entre 31 a 55 anos e com o ensino fundamental incompleto e que ganham cerca de uma renda mensal de até um salário mínimo com a venda desses produtos a qual torna necessário a complementação da renda com outros serviços para manter a subsidência da família. Portanto, embora haja um interesse na fabricação e produção desses produtos o apoio e incentivo a esse trabalho ainda é mínimo contando apenas, muitas vezes, com a vontade e persistência dos artesões desse ramo o que torna de extrema importância a criação de associações e políticas públicas que possam servir como apoio a esses trabalhadores.
\end{abstract}

Palavras-Chave: Biojóias, sustentabilidade, artesão, PFNM.

\footnotetext{
${ }^{1}$ Engenharia Florestal, Universidade Federal Rural da Amazônia, Bolsista PET, joaolucas508@@ @mail.com

${ }^{2}$ Engenharia Florestal, Universidade Federal Rural da Amazônia, Bolsista PET, thamiresdias02@gmail.com

${ }^{3}$ Engenharia Florestal, Universidade Federal Rural da Amazônia, giovanaseabra88@ gmail.com

${ }^{4}$ Engenharia Florestal, Universidade Federal Rural da Amazônia, michele.lobato99@gmail.com

${ }^{5}$ Mestre, Universidade Federal Rural da Amazônia, danilomerces@gmail.com
} 


\title{
UTILIZAÇÃO DE SEMENTES PARA BIOJÓIAS POR ARTESÕES
}

\begin{abstract}
RESUMEN
Debido a la gran biodiversidad que tiene la Amazonía como prácticas que promueven y aprovechan esta biodiversidad, deben ser valoradas para demostrar el verdadero potencial del aprovechamiento de los bosques en pie, destacando así la fabricación de bio-joyas, que si bien tienen grandes importancia ambiental, su prominencia es aún pequeña cuando se relaciona con otros productos de manejo forestal no maderables, como la extracción de frutos y aceites. De esta forma, las biojewels, así como otros productos provenientes de actividades no madereras, tienen un gran valor de sustentabilidad, cumpliendo con los requerimientos actuales del mercado mundial, sin embargo, la fabricación de biojewels aún agrega lo estético y cultural y por eso las biojewels fueron denominadas como adornos disponibles a mano con el uso de recursos naturales que valoran y difunden la cultura nacional y la biodiversidad existente en el país y que garantizan la sustentabilidad e ingresos de las familias, cumpliendo así con los requerimientos sustentables, ecológicos y sociales. Así, el objetivo de esta investigación fue identificar semillas utilizadas en artesanías en las principales ferias y plazas de Belém y la región metropolitana, además de verificar los principales productos elaborados y los valores con los que se comercializan estos productos. productores en tres ferias en la ciudad de Belém - PA. En este sentido, el mayor porcentaje de productores de biojeyas en Belém son mujeres de entre 31 y 55 años y con educación primaria incompleta y que ganan alrededor de un ingreso mensual de hasta un salario mínimo por la venta de estos productos. complementar los ingresos con otros servicios para mantener el hundimiento de la familia. Por tanto, si bien existe un interés en la fabricación y producción de estos productos, el apoyo y estímulo para este trabajo sigue siendo mínimo, apoyándose muchas veces solo en la voluntad y persistencia de los artesanos en este campo, lo que hace que la creación de asociaciones y políticas públicas extremadamente importante que sirve de apoyo a estos trabajadores.
\end{abstract}

Palabras Clave: biojewels, sostenibilidad, artesanal, PFNM

\begin{abstract}
As a result of Amazonia great biodiversity, the practices which one foment and harness this biodiversity must be vaporized with the intent to demonstrate the true potential use for the standing forest, hence, stand out the bio jewels fabrication, which although have big environmental impotence your highlight is still small when compared to other products from the non-wood forest management, like fruits and oils extraction. Thereby, as the bio jewels as the other products came from non-wood activities have a huge value to the sustainability, attending the requirements of the current World trade, however, the bio jewels fabrication continuos aggregate the aesthetic and culture and this way the bio jewels would be denominated as ornaments created manually with the utilization in natural resources which appreciate and disseminate the national culture and biodiversity from this country and guarantee the sustainability and the familiar income, thus attending the sustainable, ecologic and social issues. Thereby the objective of this research was to identify the seeds used in handcrafts from the main Belem's fairs and metropolitan region, in addition, to verify the main products handcrafted with seed and their values with ones these products are traded, for this were planned and applied a questionnaire to the artisans of bio jewels located in three fairs and squares from Belém - PA. Hence, the biggest percentage of bio jewels producers in Belém are women who have an age range between 31 and 55 years old and incomplete middle school and earning a monthly income until one minimum wage with these products sale which makes necessary the complementation with others services to maintain the familiar livelihood. Therefore, although have an interest in the fabrication and production of these products the support and encouragement of this work is still minimum considering, most of the time, just with the desire and persistence from bio jewels artisans which makes highly important the creation of associations and public policies to serve as support for these workers.
\end{abstract}

Keywords: biojewels,sustainability, artisans, NWFP. 


\section{INTRODUÇÃO}

A floresta Amazônica é uma fonte importante de recursos naturais para as atividades humanas, inclusive para a geração de renda de comunidades que dela extraem o que é necessário à sua sobrevivência (PASTORE JUNIOR \& BORGES, 2009). A maior parte do bioma amazônico encontra-se em território brasileiro, cerca de 60\%. Com isso, o território nacional possui a maior biodiversidade do mundo em termos de fauna e flora, contribuindo de forma significativa para a toda biodiversidade na região neotropical, aproximadamente $63 \%$ das linhagens das espécies existentes (ALEXANDRE ANTONELLI et al, 2018).

Saraiva (2018) ressalta o interesse crescente dos consumidores em relação aos produtos ecologicamente corretos, a exemplo das biojoias, que para Lana (2010) são produtos genuinamente ligados à cultura brasileira com um perfil sustentável. As referidas autoras também evidenciam que esses tipos produtos geram, além do lucro, uma visão ecológica e socialmente correta. Assim, ganham mais facilmente espaço no mercado nacional e internacional.

Em virtude disso, a extração de Produtos Florestais Não Madeireiros (PFNM) tornouse de suma importância para a sustentabilidade das florestas brasileiras, os PFNM's são considerados como todo produto florestal não lenhoso de origem vegetal e animal (EMBRAPA ACRE, 1998; ELIAS E SANTOS, 2016) e com alto potencial de sustentabilidade com distintas utilidades como domésticas, comerciais, culturais, religiosas e sociais (ELIAS E SANTOS, 2016).

Os PFNM's mais utilizados são as folhas, frutos, flores, cascas entre outros produtos que possuem funções ecológicas, ornamentais, medicinais, apícolas, bioquímicas, alimentícias e de artesanatos (ELIAS E SANTOS, 2016). Nesse contexto estão as sementes, que possuem funções para a alimentação, para a extração de óleos ou para a confecção de artesanatos (VALLE, 2008; ELIAS E SANTOS, 2016), a qual, quando usada para artesanato, se destina à fabricação de biojóias.

Para Nogueira (2008) as biojóias podem ser empregadas como acessórios de moda, matéria-prima natural e como amostra da biodiversidade das florestas brasileiras. Em virtude disso, possuem alto valor agregado e grande aceitação no mercado. Os materiais utilizados para a produção das biojóias são variados, podendo-se empregar distintas sementes, fibras naturais, casca de coco, conchas, madrepérola, capim, madeira, ossos, penas e escamas (SEBRAE, 2012).

Sabe-se que o artesanato é uma das atividades com muito destaque em feiras de Belém do Pará por conta de sua estética e valor cultural. Assim, entende-se como artesanato toda a 


\section{UTILIZAÇÃO DE SEMENTES PARA BIOJÓIAS POR ARTESÕES}

atividade cuja confecção depende em pelo menos uma etapa de forma direta do artesão podendo ser feita ou não com auxílio de instrumentos para sua produção (DINIZ \& DINIZ, 2007). Além disso, é importante destacar que o artesanato está fortemente vinculado às concepções da sustentabilidade em virtude da reciclagem, reutilização e a não agressão ao meio ambiente (LEITE E SEHNEM, 2018), agregando, assim, valor à prática do artesanato com PFNM's.

Desse modo o objetivo dessa pesquisa foi identificar as sementes utilizadas no artesanato nas principais feiras e praças de Belém e região metropolitana, além de verificar os principais produtos confeccionados com sementes e os valores pelos quais esses produtos são comercializados.

\section{FUNDAMENTAÇÃO TEÓRICA}

O artesanato, de acordo com Lima (2009), pode ser dividido em dois modelos: o manual e o industrializado a qual o manual estar associado a não utilização tecnológica para sua fabricação com o uso somente das mãos para fabricação das peças, desse modo, inviabilizando muitas vezes uma fabricação em série, logo, tendo uma singularidade por cada peça produzida.

Já para o artesanato industrializado há a utilização de ferramentas tecnológicas como moldes ou outras ferramentas as quais facilitem a produção em série tendo sempre características iguais nas produções das peças de artesanato (LIMA, 2009).

Portanto, o artesanato com sementes, as biojoias, de acordo com as classificações de Lima (2009) são consideradas como manuais em virtude da singularidade de cada peça produzida e de não haver uma produção em larga escala e do uso de aparatos tecnológicos.

Desse modo, as biojóias, são consideradas como adornos produzidos artesanalmente com a utilização de recursos naturais que valorizam e difundem a cultura nacional e a biodiversidade existente no país, pois têm grande exuberância de cores e formas a qual auxiliam o artesão no potencial criativo, desta forma, garantindo a sustentabilidade e a renda destes e de suas famílias e ainda constituindo um importante aspecto para a melhoria da qualidade de vida das populações tradicionais residentes em áreas próximas de florestas (CAROLINO et al, 2013)).

Outro aspecto a ser destacar é em virtude da sua a qual facilita a adesão desse produto ao mercado tanto nacional quanto internacional (SARAIVA, 2018; LANA ,2010), em decorrência da busca contemporânea por modelos de negócios sustentáveis e que ser preocupem com o meio (SOUZA et al, 2012) e acordo com Souza et al. (2012) o desenvolvimento sustentável ocorre quando há crescimento econômico, com desenvolvimento humano e qualidade ambiental. 
Candido et al. (2008) coloca que a comercialização as biojóias na Amazônia atendem principalmente ao mercado internacional, principalmente devido ao valor agregado que esses produtos de comunidades da Amazônia têm para esses compradores internacionais, esses dados são reafirmados por Souza et al. (2012) ao estudar o mercado de biojóias de outras comunidades Amazônicas.

Com isso Valle (2008) destaca que em todo o país, 8,5 milhões de pessoas estão envolvidas em atividades artesanais, gerando cerca de 2,8\% do PIB do Brasil no ano de 2008. Soares (2012) apud Carolino et al. (2012) reafirma essa tendência do artesanato em seu estudo onde apontou que em 2011 o PIB do Brasil para essa área correspondeu a 2,7\%, e em 2018 o Ministério da Indústria, Comércio Exterior e Serviços apontou uma representatividade do artesanato de $3 \%$ do PIB do Brasil a qual seria equivalente a 50 bilhões de reais com um quantitativo de 8 milhões de artesões.

Portanto, há um movimento econômico brasileiro sobre a área do artesanato. Carolino et al. (2013) afirma que a economia criativa é a força motriz do desenvolvimento do século XXI a qual o mesmo autor dividi essa economia criativa em quatro partes: patrimônio cultural, artes, mídias e criações funcionais a qual de acordo com Unctad (2008) a biojóia estaria vinculada ao patrimônio cultural. Desta maneira sendo uma representação cultural de um determinado local ou região (SOUZA et al, 2012).

Porém, mesmo com o crescente comércio desse produto sustentáveis, ecológico e socialmente justo ainda há diversas problemáticas sendo a principal, a carência de informações sobre o setor (CAROLINO et al, 2013), a mão de obra escassa e qualificada (SOUZA et al, 2012; TAVERNARD, 2010) e conhecimento técnico (TAVERNARD, 2010). Conseguintemente necessitando de mais pesquisas nessa área, assim como colocado por Carolino et al. (2013) e Souza et al. (2012).

\section{METODOLOGIA}

A pesquisa foi realizada seguindo um modelo de um projeto de levantamento com uma aplicação padrão de questionário de múltiplas escolhas para a obtenção dos dados (OLIVEIRA E SANTOS, 2012), deste modo foi visitado três feiras de artesanato localizadas em Belém: Vero-Peso, Av. Boulevard Castilhos França S/N - Comércio, Belém PA; Mercado de São Brás, Av. José Bonifácio S/N - São Brás, Belém PA e na Praça da República, Av. Presidente Vargas 814Campina, Belém Pará, no período de 4 dias aplicando questionários ao máximo de artesãos encontrados nas áreas citadas.

Foram aplicados 30 questionários, com 19 perguntas objetivas abordando sobre a 


\section{UTILIZAÇÃO DE SEMENTES PARA BIOJÓIAS POR ARTESÕES}

fabricação das peças desde a coleta do material, tipos de sementes utilizadas, o produto final e a venda dos artesanatos, desta forma tendo um objetivo de trilhar a cadeia de produção, sendo que, as questões com a qual visavam fazer o levantamento do perfil socioeconômico dos artesãos foram aplicados somente à aqueles que produzissem e vendessem o seu próprio artesanato e não realizavam a compra do produto manufaturado ou semimanufaturados de fornecedores com o intuito de qualificar essa produção.

A divisão da aplicação dos questionários seguiu a seguinte ordem; 15 na Praça da República, 9 no Ver-o-Peso e 6 em São Brás, essa divisão foi realizada de acordo com o quantitativo de artesões em cada localidade pesquisada a qual tentou abranger o máximo de artesões.

Todos os dados coletados foram analisados estatisticamente por meio do uso de gráficos, tabelas e planilhas no programa Microsoft Excel 2019, além de consultas bibliográficas.

\section{RESULTADOS E DISCUSSÃO}

Foi traçado o perfil socioeconômico dos artesãos das feiras do Ver-O-Peso, São Brás e Praça da República (figura 01), no qual se percebe que a maior parte dos artesãos é composta por mulheres de ensino fundamental incompleto com idade entre 41 a 51 anos e renda média mensal de até um salário mínimo, assim como também achado por Grangeiro e Bastos (2016) em Cariri no Ceará e Gonçalves et al. (2018) em Várzea Alegre no Ceará que obtiveram resultados semelhantes em idade, sexo predominante e salários, no entanto, para escolaridade Grangeiro e Bastos (2016) obtiveram resultados próximo a este trabalho enquanto que Gonçalves et al. (2018) verificou uma amostra com uma escolaridade mais elevada.

Figura 01: Perfil dos artesãos entrevistados nas feiras no município de Belém - PA.

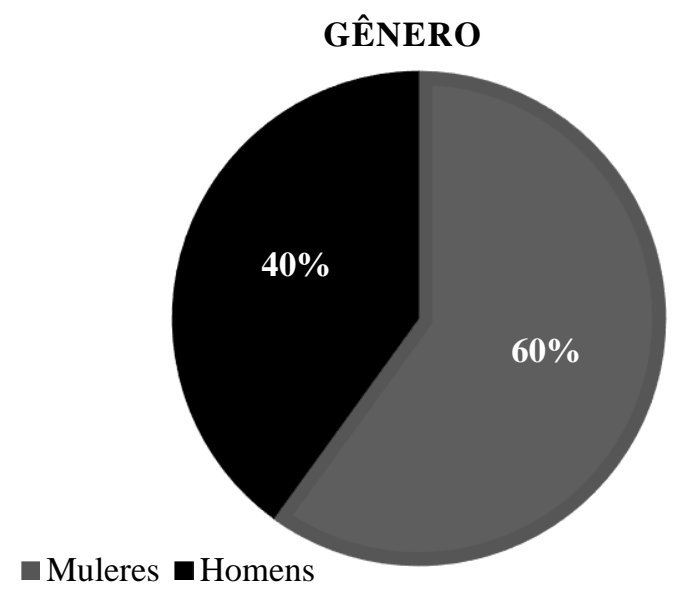

\section{RENDA MÉDIA MENSAL}

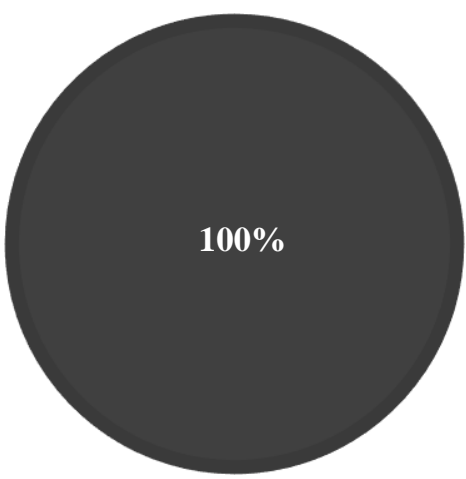

Até 1 salário mínimo 
FAIXA ETÁRIA

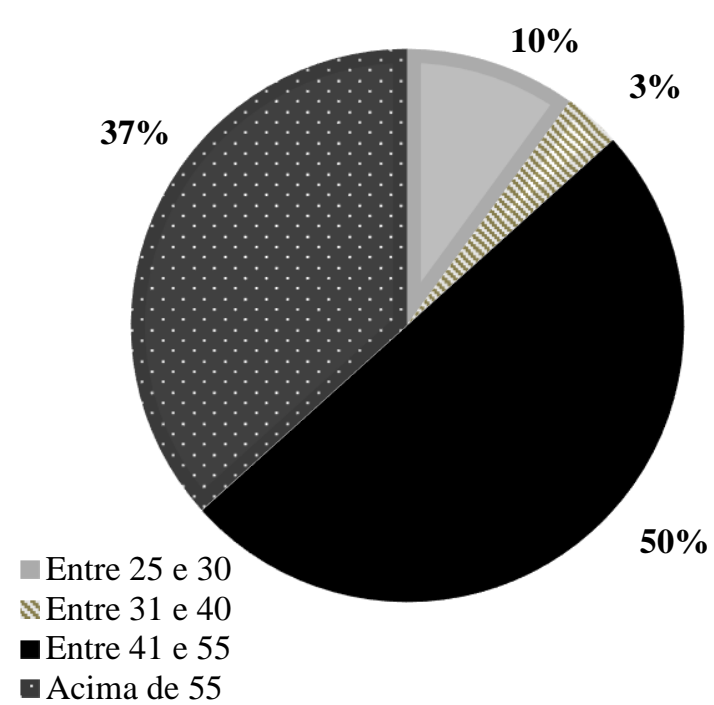

ESCOLARIDADE

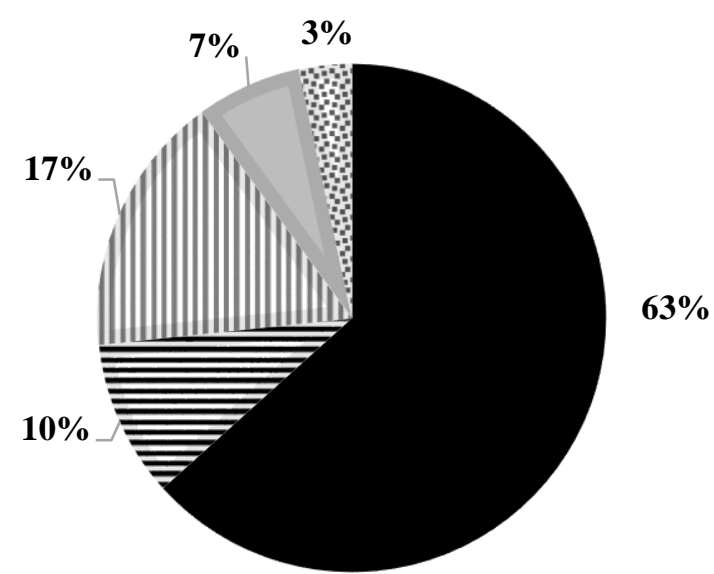

- Fundamental Incompleto = Fundamental Completo III Médio Incompleto $\quad$ Médio Completo $n$ Superior Incompleto

Fonte: Própria, 2021.

O perfil dos artesões se demostra importante em virtude da necessidade das políticas públicas a qual serão feitas para atender essa parte da sociedade onde, tendo a escolaridade, o sexo predominante e a idade ser pode os objetivos das políticas mais focado para um determinado público podendo ter, dessa forma, uma maior taxa de sucesso nas aplicações delas.

No entanto, enquanto a satisfação salarial, todos os artesãos estudados demonstraram satisfeitos com sua renda obtida mensalmente, distintamente ao encontrado por Grangeiro e Bastos (2016) no qual apenas 70\% demonstraram-se satisfeitos com sua renda obtida, em relação a trabalhos complementares dos artesãos, encontrou que apenas cerca de $13 \%$ dos artesãos realizavam trabalhos além do artesanato, resultados dispare ao encontrado por Grangeiro e Bastos (2016) onde cerca de 30\% dos entrevistados apresentavam uma renda advinda de outras atividades laborais. Esse cenário demonstra que a questão da satisfação com o trabalho de artesão de biojoias é distinta entre as diversas regiões do Brasil estando vinculado a um aspecto cultural e social assim como colocado por Carolino et al. (2013).

Em relação aos tipos de sementes utilizadas no artesanato na feira de Belém, quadro 01, se pode verificar que a maioria adquire a partir de beneficiadores (pessoas que coletam as sementes para fazer todo processo de tratamento) ou de lojas específicas para venda de sementes, resultado semelhante ao encontrado por Gonçalves et al. (2018) e Vale e Grangeiro (2012) nos quais uma minoria realiza a coleta diretamente da natureza. Tal evento pode ser em virtude da dificuldade da obtenção dos recursos na natureza, a qual muitas vezes é necessário equipamentos adequados para a realização da coleta de sementes a qual muitos artesãos não têm acesso. 


\section{UTILIZAÇÃO DE SEMENTES PARA BIOJÓIAS POR ARTESÕES}

Quadro 01: Sementes usadas na confecção do artesanato em Belém - PA.

\begin{tabular}{|c|c|c|}
\hline Nome Vulgar & Nome Científico & Porte \\
\hline Açaí & Euterpe oleracea Mart. & Palmeira \\
\hline Saboneteira & Sapindus saponaria L. & Árvore \\
\hline Bacaba & Oenocarpus bacaba Mart. & Palmeira \\
\hline Olho-De-Boi & Leucanthemum vulgare (Vaill.) Lam. & Árvore \\
\hline Tento & Adenanthera pavonina Linnaeus & Árvore \\
\hline Pupunha & Bactris gasipaes Kunth. & Palmeira \\
\hline Tucumã & Astrocaryum aculeatum G.Mey. & Palmeira \\
\hline Murucí & Byrsonima crassifolia (L.) Kunth. & Árvore \\
\hline Miriti & Mauritia flexuosa L.f. & Palmeira \\
\hline Bole-Bole & Ormosia coutinhoi Ducke. & Árvore \\
\hline Galá-Galá & & $* * *$ \\
\hline & F** não identificado. & \\
\hline & Fonte: Própria (2021). &
\end{tabular}

Embora todas as sementes utilizadas sejam da região amazônica nota-se que em Belém há a utilização de poucas espécies quando comparado com outras regiões, a exemplo de Altamira - PA a qual foi estudada por Campos (2014) onde se verificou o uso de 29 espécies de sementes no artesanato local. Apesar dos dois estudos terem sido feitos no mesmo estado, nota-se que em Altamira a biodiversidade de sementes utilizadas no artesanato e significativa em comparação a Belém, isso pode advir do fato do município estar mais próximo da área de floresta e de que os artesãos ainda terem o auxílio de cooperativas que fornecem maquinários para o preparo da semente para processos como secagem, polimento, imunização e envernização, distintamente dos artesões entrevistados das principais feiras de Belém - PA a qual nenhum citou a ajudar de alguma cooperativa. Essa falta de auxílio ser torna um aspecto de grande impacto para os artesões de Belém - PA tanto na diversidade de sementes utilizadas quanto no beneficiamento das sementes, esse fator ser tornou evidente no levantamento

Após a verificação nas feiras de artesanato ser foi observado as frequências das sementes utilizadas (figura 02) constatou-se que a mais usada é o açaí, mas especificamente a espécie Euterpe precatoria Mart. espécie mais comum em Manaus - AM, os artesões explicam que essa espécie quando lixada apresenta uma coloração embranquecida o que facilita a fixação de outras cores ajudando na estética do produto, além de não ressecar rápido, ao contrário da espécie encontrada no Pará em maiores quantidades, a Euterpe oleracea Mart. que ao ser lixada tem uma coloração marrom dificultando fixação de cores além de resseca rápido o que gera a necessidade do uso de óleo de amêndoas para a hidratação da semente. 
Figura 02: Sementes utilizadas pelos artesões nas feiras de Belém - PA.

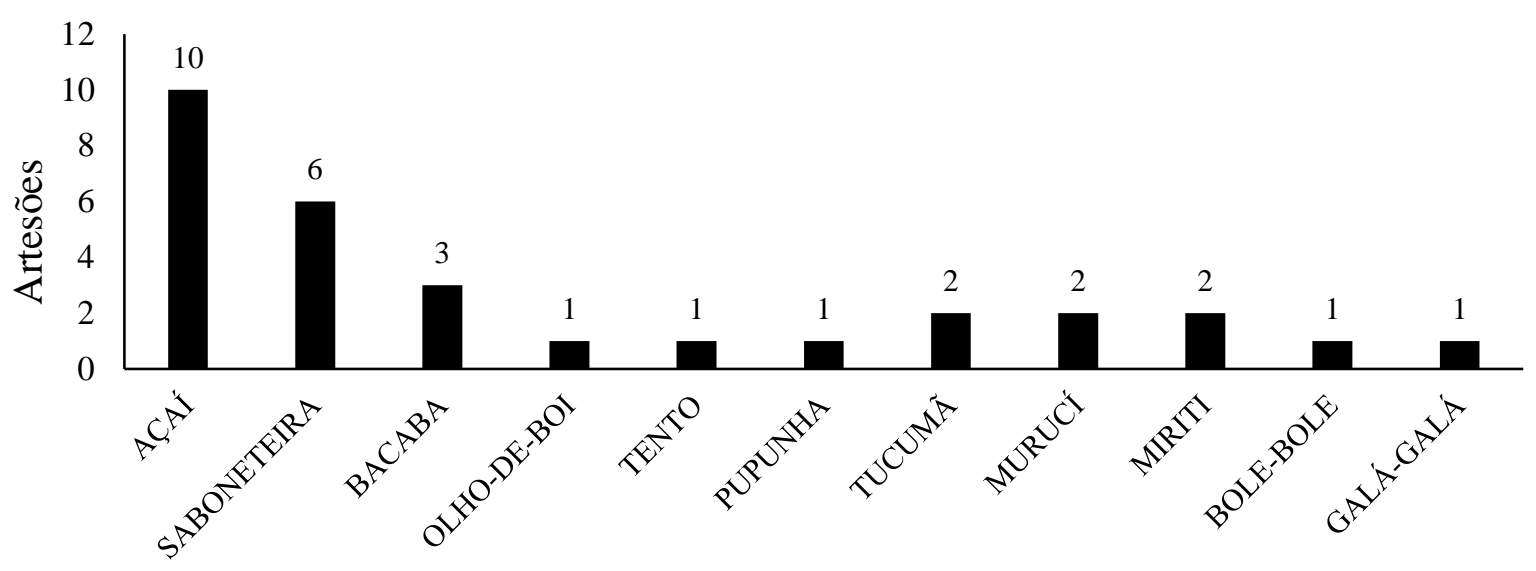

Fonte: Própria (2021).

Nos estudos de Campos (2014); Valle (2008) o açaí, Euterpe oleracea Mart., também aparece como uma das espécies a qual são empreendida no artesanato, mas deve-se levar em consideração que nos três estados onde foram realizadas as pesquisas os artesões tem conexão com cooperativas que auxiliam no tratamento das sementes o que facilitam a criação do artesanato, essa cooperação entre associação e artesão também foi achado de forma significativa no trabalho levantado por Gonçalves et al. (2018) no qual se percebe essa ligação, embora que, não seja maioria quando ser destaca o aspecto da venda, ou seja, há, em sua maioria, o auxílio das cooperativas somente no tratamento e coleta de sementes para o trabalho e não para facilitar a venda do produto final.

Além disso, observa-se também na figura 02 a distribuição do uso das sementes para a construção das biojóias, e se percebe que o Tento da Carolina (Adenanthera pavonina Linnaeus) é a semente menos utilizada, apesar da sua exuberância (figura 03), isso dá por apresentar características que dificultam a produção do artesanato, como a dureza e facilidade na proliferação de fungos, mesmo aspectos aplicados para as sementes de Olho de Cabra (Ormosia arboria (Vell.) Harms) (figura 04). Os artesões também ressaltam que sementes escorregadias dificultam o processo de perfuração e construção das peças, característica destacada nessas duas espécies de sementes.

Figura 03: Semente de tento da carolina (Adenanthera pavonina Linnaeus) 


\section{UTILIZAÇÃO DE SEMENTES PARA BIOJÓIAS POR ARTESÕES}

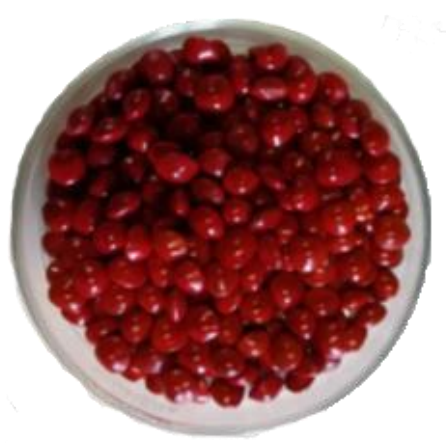

Fonte: Própria (2021).

Figura 04: Semente olho de cabra (Ormosia arboria (Vell.) Harms)

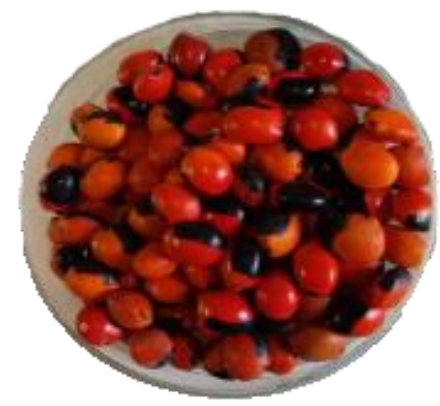

Fonte: Própria (2021).

Portanto, embora o aspecto de beleza da semente seja um fator de grande importância para a produção de biojóias, ainda ser deve considerar questões de beneficiamento, haja vista que, sementes a qual possuem um grau muito elevado para coleta, armazenamento ou até mesmo para trabalhar são rejeitadas por parte de muitos artesões assim como demostrado no trabalho.

Desta forma, de acordo com o questionário aplicado, outra característica que os artesões de Belém levam em consideração para escolher as sementes é através da boa qualidade (tabela 01), que em virtude de não terem o acesso aos mecanismos apropriados para a conservação das sementes por longos períodos de tempo optam por aquelas que não apresentam contaminações ou lesões além de terem resistência a esses fatores e a outros do meio ambiente.

No entanto, Campos (2014) verificou em seu estudo que o principal critério foi a boa aparência, ou seja, o embelezamento ou a estética da matéria prima, tal fator decorre dos artesãos de Altamira não precisarem armazenar as sementes por longos períodos de tempo por estarem próximos a fonte da matéria prima (floresta) além de possuírem apoio de cooperativas a qual permite muitas vezes a coleta do material para trabalho.

Tabela 01: Critérios usados pelos artesões para a escolha das sementes do artesanato, boa qualidade (resistência a patógenos e lesões externas), boa aparência (estética e apresentação da semente) e preço. 


\begin{tabular}{cc}
\hline Critérios utilizados na escolha das sementes & Quantidade \\
Boa qualidade & 16 \\
Boa aparência & 10 \\
Bom preço & 7 \\
\hline
\end{tabular}

Fonte: Própria (2021).

Em relação a utilização das sementes para o trabalho artesanal se obteve que há diversas utilidades (tabela 02), porém os artesões de Belém fixaram-se em sua maioria na produção de biojóias, como cordões, brincos, pulseiras, entre outros ornamentos estéticos (figura 04, 05 e 06), essa característica também foi encontrada por Grangeiro e Bastos (2016) demostrando uma tendência dos artesões para fabricação de biojóias quando utilizado componentes vegetais.

Tabela 02: Principais artesanatos e valores correspondentes.

\begin{tabular}{lll}
\hline Principais Artesanatos & $\mathrm{N}^{\circ}$ De Artesãos Que Produzem & Valores \\
Biojóias & 26 & $\mathrm{R} \$ 5,00$ à $\mathrm{R} \$ 60,00$ \\
Chaveiros & 4 & $\mathrm{R} \$ 10,00$
\end{tabular}

Fonte: Própria (2021)

Outro aspecto a ser ressaltado é que embora cada local de estudo seja pertencente ao mesmo estado há uma singularidade e peculiaridade de produção que muitas vezes depende do processo de produção com citado por Gonçalves et al. (2018); Carolino et al. (2013), ou seja, fatores vinculados a aspectos geográficos, culturais e contexto social tornam cada produção artesanal singular, como demostrado nas figuras 04,05 e 06, a qual ser nota uma distinção entre as produções das biojóias em virtude de depender de uma elaboração complexa e sistemática do convívio do artesão com o meio ao qual está inserido, logo, sendo uma representação cultural de um local ou região.

Figura 04: Biojóias produzidas pelos artesões do Mercado de São Brás. 


\section{UTILIZAÇÃO DE SEMENTES PARA BIOJÓIAS POR ARTESÕES}

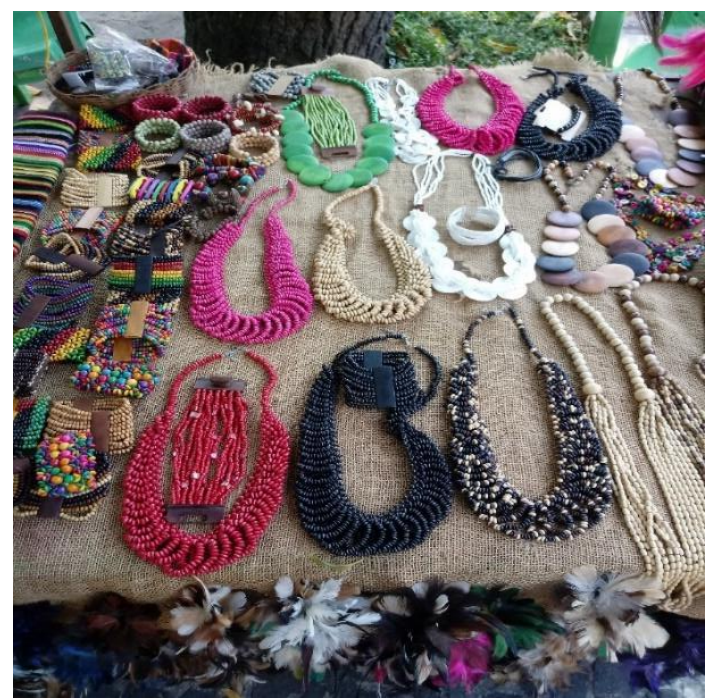

Fonte: Própria (2021).

Figura 05: Biojóias produzidas pelos artesões no Ver o Peso.

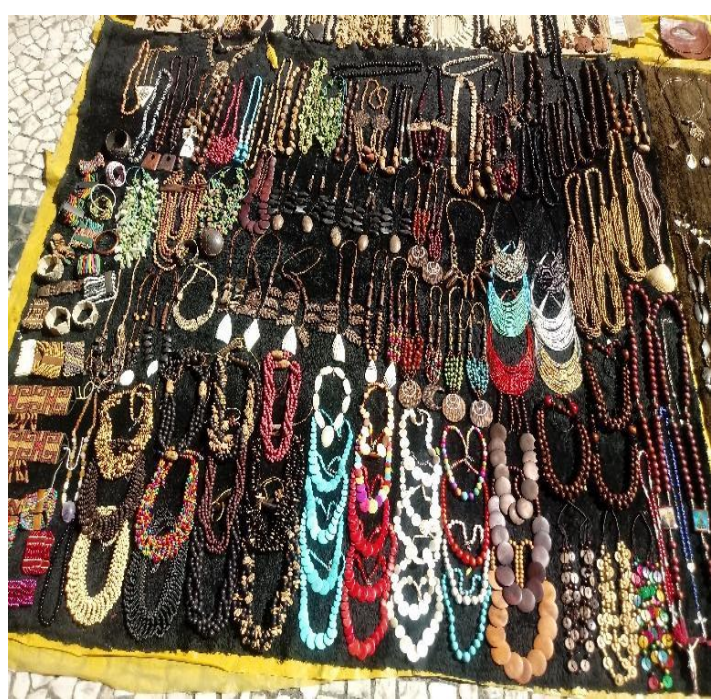

Fonte: Própria (2021).

Figura 04c: Biojóias produzidas pelos artesões da praça da República. 


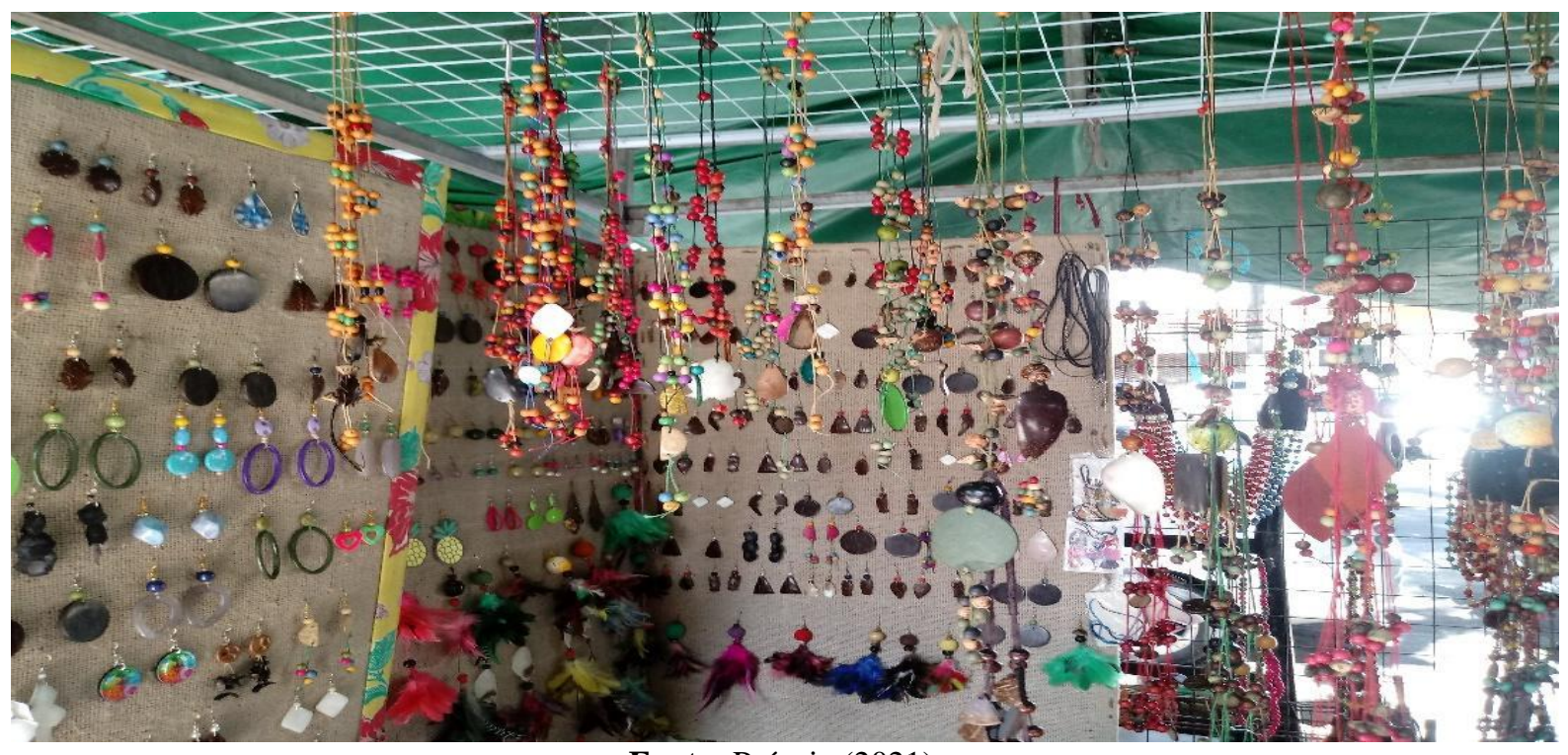

Fonte: Própria (2021).

\section{CONCLUSÕES}

Embora haja uma grande valorização cultural na região de Belém - PA o trabalho com as biojóias com sementes ainda é pouco incentivado principalmente em relação com o apoio para obtenção de sementes quando comparado com outras feiras, além de que as sementes mais utilizada na feira estudada foram da espécie Euterpe precatória Mart. a qual é mais comum no estado de Amazonas distintamente do Pará que teria como destaque a Euterpe oleracea Mart. em virtude de sua melhor trabalhabilidade.

Deste modo, é fundamental programas de incentivos à esses artesões tanto como forma de incentivo financeiro e aperfeiçoamento quanto para a valorização da cultura local por meio da estética das biojoias e dos demais ornamentos.

\section{REFERÊNCIAS}

ANTONELlI, A.; ZIZKA, A.; CARVALHO, F. A.; SCHARN, R.; BACON, C. D.; SILVESTRO, D.; CONDAMINE, F. L. Amazonia is the primary source of neotropical biodiversity. Proceedings Of The National Academy Of Sciences, United States of America, v. 115, n. 23, p. 6034-6039, 14 maio 2018. Proceedings of the National Academy of Sciences. http://dx.doi.org/10.1073/pnas.1713819115.

CAMPOS, J.A; HAMADA, M.O.S. Levantamento das sementes florestais utilizadas na confecção de artesanato no município de Altamira, Pará. Enciclopédia Biosfera, Goiânia, v. 10, n. 18, p. 2099, jul. 2014.

CANDIDO, S.E.A.; SOULÉ, F.V.; PIRES, M.B. Desenvolvimento e Implantação de Mini Fábricas de Produtos Florestais Não Madeireiros em Comunidades Ribeirinhas da Amazônia: A Experiência do Núcleo de Apoio à População Ribeirinha da Amazônia. XXVIII Encontro Nacional De Engenharia De Produção A Integração De Cadeias Produtivas Com A Abordagem Da Manufatura Sustentável., 2008, Rio de Janeiro - RJ. Anais. Encontro Nacional De 


\section{UTILIZAÇÃO DE SEMENTES PARA BIOJÓIAS POR ARTESÕES}

Engenharia De Produção A Integração De Cadeias Produtivas Com A Abordagem Da Manufatura Sustentável.

CAROLINO, J.; SOARES, P. V. D.; CANDEIAS, L. M. M.; NEWMAN, D. T. C.; NEWMAN, J. A. Economia Criativa Sustentável: Biojoias. $51^{\circ}$ Congresso da SOBER: Novas Fronteiras da Agropecuária no Brasil e na Amazônia: Desafios da sustentabilidade. Vitória - Es - Brasil. Jun 2013. Anais. Sociedade Brasileira de Economia, Administração e sociologia Rural (SOBER). DOI:10.13140/RG.2.2.22660.78726.

DINIZ, M.; DINIZ, M. J. T. Arranjo produtivo do artesanato na Região Metropolitana de Belém. Uma caracterização empírica. Novos Cadernos NAEA. v.10, n.2. 2007. DOI: http://dx.doi.org/10.5801/ncn.v10i2.103.

ELIAS, G. A.; SANTOS, R. Produtos Florestais Não Madeireiros E Valor Potencial De Exploração Sustentável Da Floresta Atlântica No Sul De Santa Catarina. Ciência Florestal. Santa Catarina - SC. v. 26, n. 1, p. 249-262, jan.-mar., 2016. DOI: http://dx.doi.org/10.5902/1980509821117.

Empresa Brasileira de Pesquisa Agropecuária - EMBRAPA. Bijuterias, adornos e artesanatos uso de sementes de espécies florestais como gemas orgânicas. 2009. Disponível em: https://www.infoteca.cnptia.embrapa.br/infoteca/bitstream/doc/573713/1/fd080001.pdf.

Acesso em: 16 jun. 2019.

GOnÇAlves, M.; GRANGEIRO, R. R.; JÚNIOR, J. T. S. O Perfil do Artesão e de sua Produção na Cidade de Várzea Alegre - Ceará. Id On Line Revista Multidisciplinar e de Psicologia. Cariri - CE, v. 12, n. 41, p. 530 - 550, 2018. DOI: https://doi.org/10.14295/idonline.v12i41.1241.

GRANGEIRO, R. R.; BASTOS, A. V. B. Organização do Trabalho Artesanal: Examinando Aspectos de Inovação e Visibilidade do Artesanato no Cariri Cearense. Revista de Psicologia, Fortaleza, v.7 n.2, p. 33-48, jul./dez. 2016.

LANA, S. L. B.; PEREIRA, L. K.; SILVA, A. C. M.; BENATT, L. P. Design de biojoias: desenvolvimento de produtos com perfil sustentável. V Encontro Nacional da Anppas. Florianópolis - SC, out. 2010. Anais. Encontro Nacional da Anppas.

LEITE, A. A. V.; SEHNEM, S. Proposição de um modelo de gestão sustentável e competitivo para o artesanato. Cad. EBAPE.BR, Rio de Janeiro, v. 16, n. 2, p. 264-285, 2017. DOI: https://doi.org/10.1590/1679-395164057.

LIMA, R. G. Artesanato e arte popular: duas faces de uma mesma moeda. Brasília: Ministério da cultura - Centro Nacional de Folclore e Cultura Popular, 2009. Disponível em: http://www.cnfcp.gov.br/interna.php?ID_Secao=96, acesso em: 25/08/2021.

NOGUEIRA, E. A. Insetos broqueadores de sementes e aproveitamento de sementes para confecção de biojóias e artesanato. Trabalho de conclusão de curso (engenheira florestal) Universidade Federal Rural do Rio de Janeiro. f. 33. Seropédica, RJ, jul. 2008.

PASTORE JUNIOR, Floriano; BORGES, Vag-Lan. Produtos florestais não-madeireiros: Processamento, coleta e comercialização. ITTO, FUNATURA, IBAMA, LATEQ-UnB. Projeto 
ITTO 143/91 Ver. 2(I) 54 p. Brasília, 1998. Relatório Técnico.

SANTOS, T. S.; NORONHA, R. G.; SARAIVA, G. R. C. Sementes em correspondência e os aspectos da sustentabilidade na comunidade do Maracanã, São Luís - MA. $7^{\circ}$ Simpósio Design Sustentável, Recife-PE. Blucher. v. 6 n. 3 out 2019. DOI: 10.5151/7dsd-3.2.055.

SARAIVA, G. R. C.; SANTOS, T. S. Joias do Maracanã: Tingimento natural de sementes. $13^{\circ}$ Congresso de Pesquisa e Design - P\&D. Joinville -SC. São Paulo: Blucher. p. 476-488, 2018. Anais. DOI 10.5151/cid2017-42.

Serviço Brasileiro de Apoio às Micro e Pequenas Empresas (SEBRAE). Ideias de Negócios: Produção de $\quad$ Biojóias. $2012 . \quad$ Disponível https://bibliotecas.sebrae.com.br/chronus/ARQUIVOS_CHRONUS/bds/bds.nsf/F08FE871B6 9E106283257A33005B6812/\$File/NT0004773E.pdf. Acesso em: 20 jul. 2020.

OLIVEIRA, A. M. B. e SANTOS, J. F. O questionário como instrumento de apreensão da realidade. XV SemeAD - Seminário de Administração, 2012.

TAVERNARD, S. R.; LISBOA, T. C. Desenvolvimento sustentável e empreendedorismo: o beneficiamento e comercialização de sementes da Amazônia no município de Porto Velho, RO. Faculdade de Ciências Administrativas e de Tecnologia (FATEC), Porto Velho - RO. 2010 .

The United Nations Conference On Trade And Development (UNCTAD). Creative Ecomony Report 2008: The Challenge of Assessing the Creative Economy: towards informed Policymaking. Genebra: UNCTAD/United Nations, 2008.

VALE, C. A. R.; GRANGEIRO, R. R. Indicadores de design para a sustentabilidade no artesanato de Juazeiro do Norte/CE e suas relações com a economia solidária. Cadernos Gestão Social, v. 3, n. 1, p. 39-52, 2012.

VALLE, M. J. L. V. Sementes florestais utilizadas em artesanato no rio de janeiro. 2008. 43 f. Trabalho de conclusão de curso (Engenheira Florestal) - universidade federal rural do rio de janeiro, Rio de Janeiro, 2008. 